\title{
Gun Violence Exposure and Experiences of Depression Among Mothers
}

\author{
Christine Leibbrand ${ }^{1}$ (D) $\cdot$ Frederick Rivara $^{2} \cdot$ Ali Rowhani-Rahbar ${ }^{2}$
}

Accepted: 15 December 2020 / Published online: 13 January 2021

(C) Society for Prevention Research 2021

\begin{abstract}
Gun violence is a uniquely prevalent issue in the USA that disproportionately affects disadvantaged families already at risk of health disparities. Despite the traumatic nature of witnessing gun violence, we have little knowledge of whether exposure to local gun violence is associated with higher risks of depression among mothers, whose symptoms of depression are likely to have spillover effects for kin. We examined the association between exposure to gun violence in mothers' neighborhoods and their experiences of depression using longitudinal Fragile Families and Child Wellbeing Study data $(n=4587)$ in tandem with lagged outcome and fixed effect models. We find that mothers who witness at least one shooting in their neighborhoods or local communities exhibit more symptoms of depression and are 32-60\% more likely to meet criteria for depression than mothers who do not witness a shooting. We also find that witnessing a shooting is associated with increases in parental aggravation, which is partially mediated by maternal depression. Given this and other previously documented spillover effects of mothers' mental health on children and family members, these findings have important implications for mothers' wellbeing and their kin. Further, we observe substantial racial and socioeconomic disparities in exposure to gun violence, suggesting that gun violence may heighten health disparities and drawing attention to the importance of providing mental health resources in communities that are most affected by gun violence.
\end{abstract}

Keywords Gun violence $\cdot$ Depression $\cdot$ Maternal outcomes $\cdot$ Fragile Families and Child Wellbeing Study

\section{Introduction}

The USA ranks first among high-income countries for the number of gun deaths and gun injuries per capita, with 39,740 people killed by guns in 2018 (Center for Disease Control \& Injury Prevention, Web-Based Injury Statistics Query and Reporting Systems (WISQARS) 2020). The costs of gun violence for survivors are profound and include a higher likelihood of suffering from PTSD (Montgomerie et al. 2015; Ranney et al. 2019), perpetrating violence (Rowhani-Rahbar et al. 2016), carrying guns (Beardslee et al. 2018), and experiencing subsequent reinjury or death than those who experience other forms of injury (Rowhani-Rahbar et al. 2015; Fahimi et al. 2016). However, gun violence is likely to have an important,

Christine Leibbrand

cleibb@uw.edu

1 Center for Studies in Demography and Ecology, University of Washington, 218 Raitt Hall, Seattle, WA 98195, USA

2 Firearm Injury \& Policy Research Program, Harborview Injury Prevention \& Research Center, University of Washington, Seattle, WA, USA underappreciated impact on community members who hear about or witness gun violence. The impact of gun violence on mothers is particularly understudied. This gap in the literature is important because mothers' mental health and wellbeing have important spillover effects for their children and partners (Bagner et al. 2010; Cummings and Davies 1994; Elgar et al. 2004; Goodman et al. 2011; Yeh et al. 2016). Examining the determinants of mothers' mental health therefore offers important insights into how to improve mothers' wellbeing, as well as the wellbeing of her family. In this study, we examined whether witnessing gun violence in one's community has associations with mothers' symptoms of depression, probabilities of meeting depression criteria, and reports of parental aggravation. In doing so, we point to important externalities associated with the US's gun violence epidemic.

\section{Background}

\section{Community Violence and Wellbeing}

Prior research illustrates that individuals who are exposed to local violence have greater risks of experiencing mental health 
concerns including anxiety, PTSD, and depression, the latter of which is the focus of this study (Clark et al. 2008; Fowler et al. 2009; Rossin-Slater et al. 2019; Theall et al. 2017; Wilson-Generson and Pruchno 2013; Wilkinson et al. 2008). These associations hold for those who are victimized by violence and for those who are indirectly exposed to violence, by witnessing or hearing about it in their communities (Gergo et al. 2020; Fowler et al. 2009; Rossin-Slater et al. 2019).

Local violence can also exacerbate risk factors for depression by preventing individuals from going outside and socializing, thereby corresponding to physical inactivity (Kneeshaw-Price et al. 2015; Yu and Lippert 2016), social isolation (Barnes et al. 2006; Cohen-Mansfield et al. 2016), and lower social cohesion among neighbors (Kingsbury et al. 2020; Newbury et al. 2018). Low social cohesion has even been found to exacerbate the relationship between violence exposure and adverse mental health outcomes (Kingsbury et al. 2020; Newbury et al. 2018). Additionally, neighborhoods with a greater prevalence of gun violence tend to be more socioeconomically disadvantaged, racially segregated, and have lower access to healthcare resources (Kane 2011; Knopov et al. 2019; Williams and Collins 2001; Wong et al. 2020). As such, local violence can have direct and indirect impacts on community members' mental health and may exacerbate socioeconomic and racial disparities in health and wellbeing.

While prior research has made important strides in highlighting the impacts of local violence on individuals' mental health, this research has largely not examined the relationship between gun violence in one's community and individuals' risks of depression. Instead, existing studies have largely focused on crime rates or cumulative measures of violence exposure that combine exposure to gun violence with other forms of violence such as stabbings, muggings, and physical fights (Gergo et al. 2020; Clark et al. 2008; Fowler et al. 2009; Huang et al. 2018; Wilson-Genderson and Pruchno 2013). This is an important gap in the literature because gun violence is far more likely to lead to the death or injury of victims and bystanders than other types of violence such as stabbings or physical fights and, as such, may be especially traumatizing for witnesses (Wells and Horney 2002). Indeed, residents of violent neighborhoods report fears that they or their loved ones will be the victims of gun violence (Opara 2020). Victimization with a gun is also associated with significantly greater mental health distress than victimization with other weapons (Kagawa et al. 2018, 2020; Langton and Truman 2014). Furthermore, gun use is associated with and enables other forms of violence such as gang violence (Stretesky and Pogrebin 2007) and suicide (Shenassa et al. 2003). Gun violence may therefore have an especially comprehensive association with local occurrences of crime, injury, and death and thereby have important, enduring associations with depression and wellbeing among community members.
Moreover, much of the prior literature has examined the impact of local violence on children, adolescents, and victims and perpetrators. Few studies have examined the impact of local violence on mothers. However, maternal depression is important for mothers' wellbeing, for the wellbeing of her family members, and for familial dynamics. For example, maternal depression is associated with aggravation in parenting (also referred to as parenting stress), harsher parenting practices, negative attachment between parents and children, and impaired family functioning, including lower quality relationships between parents and worse familial problem-solving (Elgar et al. 2004; Erickson et al. 2019; Wolford et al. 2019; Yeh et al. 2016). Given these relationships, it is perhaps unsurprising that prior research has found that maternal depression is associated with children's behavioral problems, risks of depression, and attachment styles in the short and long term (Bagner et al. 2010; Cummings and Davies 1994; Elgar et al. 2004; Goodman et al. 2011; Pratt et al. 2019). Examining the determinants of maternal depression is therefore important for understanding the wellbeing of mothers and their families.

The few studies that have examined these associations for adult women's outcomes have largely been smaller scale, focusing on specific areas or subsets of mothers, such as those recovering from substance use disorders (Clark et al. 2008; DeSantis et al. 2016; Evans et al. 2011). An important exception to this is a study by Huang et al. (2018) that examined the association between health outcomes and a dichotomous measure indicating whether mothers witnessed or were victimized by any type of violence, including shootings, attacks with other forms of weapons, and being hit. The authors found that exposure to violence 2 years prior was associated with health problems, substance abuse, and depression. While that study made very important contributions to the literature on the effects of violence exposure on individuals' health, it did not separately examine exposure to community violence from victimization and did not focus on the association of gun violence with mothers' outcomes. It also explored the associations over a relatively limited 2-year time frame. It is therefore unclear the extent to which community gun violence specifically is associated with depression among mothers.

\section{This Study}

In this study, we help fill these gaps in the literature by focusing on exposure to gun violence specifically and mothers' symptoms and diagnoses of depression for a large sample of mothers across 20 US cities. We used longitudinal Fragile Families and Child Wellbeing Study (FFCWS) data and examined whether witnessing gun violence in one's local community was associated with mothers' symptoms of depression, using three different depression outcome measures. We 
also examined whether witnessing gun violence was directly and indirectly associated with parental aggravation. Our findings highlight the externalities associated with gun violence and contribute to the literature on the social factors that shape parenting practices and children's outcomes. Further, because gun violence disproportionately impacts under-resourced communities and communities of color (Overstreet 2000; Tracy et al. 2019), our findings are important for understanding socioeconomic and racial disparities in wellbeing.

\section{Data and Methods}

The FFCWS is a longitudinal survey that followed 4898 children born in 1998 and their parents at the child's birth and at ages $1,3,5,9$, and 15 . The FFCWS randomly selected 20 US cities with populations of 200,000 or more and selected hospitals within those cities. ${ }^{1}$ The FFCWS oversampled unmarried, low-income parents and is therefore not nationally representative. However, because individuals with lower socioeconomic statuses are more likely to be exposed to gun violence (Overstreet 2000; Tracy et al. 2019), the FFCWS captures a sample that is disproportionately affected by gun violence and so is of special interest to this study.

We used data from waves 3-6 when children were 315 years old because these were the years for which we had information on mothers' exposure to violence in their communities. We studied approximately 4587 mothers for whom we had valid responses to the depression measures in at least two survey waves (the sample sizes varied across models depending on the outcome and method used, as described below). We did not include fathers because fathers were asked a more limited set of questions than mothers in most years. Missing values on the covariates were imputed using chained equations and imputing the dataset 10 times using STATA 16's "chained" command. The only pattern we observed in our missing data was that individuals who were missing data on neighborhood poverty rates were more likely to be missing information on county-level crime rates.

The FFCWS data are largely publicly available, though we also used restricted access data on the characteristics of respondents' Census tracts and counties of residence to help account for characteristics of the residential environment. This research project was approved by the institutional review board of the Human Subject Division at the University of Washington.

\footnotetext{
${ }^{1}$ These cities cover all regions in the USA and include Oakland, Austin, Baltimore, Detroit, Newark, Philadelphia, Richmond, Corpus Christi, Indianapolis, Milwaukee, New York, San Jose, Boston, Nashville, Chicago, Jacksonville, Toledo, San Antonio, Pittsburgh, and Norfolk.
}

\section{Depression}

The FFCWS measured depression using the Composite International Diagnostic Interview-Short Form (CIDI-SF) (Kessler et al. 1998). The CIDI-SF has been used in numerous epidemiological and research studies, and the questions that comprise it are consistent with those included in the Diagnostic and Statistical Manual of Mental DisordersFourth Edition (Bendheim-Thoman Center for Research on Child Wellbeing 2020). The CIDI-SF included 15 questions related to whether respondents had feelings of depression or anhedonia for a period of at least 2 weeks during the prior 12 months. These 15 questions included all those used for diagnosing major depression with the CIDI. They did not include questions from the full CIDI questionnaire that are not necessary for diagnosing depression, including respondents' level of contact with healthcare providers and the recency of their symptoms.

Respondents were first asked if they had felt depressed and/or unable to enjoy things for a period of at least 2 weeks since the prior interview and if those feelings lasted most of the day, every day during that 2-week period. Those who agreed that they had feelings of depression or anehedonia most of the day, every day for a 2-week period, were then asked 15 subsequent questions about their depressive symptoms. These questions concerned whether respondents experienced a loss of interest, tiredness, weight changes, sleep problems, trouble concentrating, feelings of worthlessness, and thoughts about death and the frequency of those symptoms (these questions were not asked of those who did not have a 2 -week period of depressive feelings that lasted most of the day). Respondents who reported at least 3 symptoms of depression most of the day during that period met the conservative threshold for diagnosing depression. FFCWS created a dichotomous variable indicating whether respondents met the conservative depression criteria, with those who meet the conservative depression criteria receiving a value of 1 , and those who did not meet the conservative depression criteria receiving a value of 0 . Respondents who reported at least 3 symptoms of depression half of the day met the liberal depression criteria and were scored a " 1 " in a dichotomous indicator variable. More information on these scales is provided in FFCWS's public data guide (Bendheim-Thoman Center for Research on Child Wellbeing 2020).

In this study, we examined depression in three ways. We examined the probabilities that respondents met the (1) liberal and (2) conservative thresholds for depression and (3) we constructed a continuous measure of depression symptoms. The third outcome was developed by standardizing the component measures to have a mean of 0 and standard deviation of 1 and summing the results from the 15 CIDI-SF questions into 
a standardized scale using STATA 16's alpha command. It was important to standardize each measure because our CIDI-SF questions had varying scales. Some of the CIDI-SF questions were dichotomous (yes/no), while others concerned the frequency of symptoms and were ordinal. Standardizing each measure addressed the different scales of these questions. Those who had no symptoms of depression were given a score of 0 . This index had an alpha score of 0.9808 , indicating it is highly reliable.

\section{Exposure to Gun Violence}

Mothers' exposure to gun violence was measured with a dichotomous variable representing whether mothers reported that they saw someone else get shot 1 or more times in the past year in their community $(1=y e s, 0=n o)$. Mothers were told to only respond about shootings they had seen in their local community or neighborhood and to not include shootings they witnessed in their home or on TV. Mothers were asked this question in waves 3-6.

\section{Covariates}

In our regressions, we included a lagged outcome variable representing mothers' symptoms or diagnoses of depression in the previous wave to account for preexisting mental illness. We also accounted for the mother's race/ethnicity (White, Black, Latinx, Other), as well as the mother's educational attainment and employment status, logged household income, and whether the household was in poverty. ${ }^{2}$ These latter measures helped account for the household's socioeconomic status, which, as noted above, is important for mothers' risk of depression and exposure to violence. We controlled for the number of children in the household, whether the mother was married or cohabiting, and whether she was cohabiting with the father of the focal child. Additionally, we included state fixed effects, the logged violent crime rate in the county, and the percentage of individuals in the respondents' neighborhood (Census tract) who were below poverty level. These contextual variables helped address prior findings that structural disadvantage in one's neighborhood is associated with individuals' risks of depression and exposure to violence (Dawson et al. 2019; Knopov et al. 2019; Wong et al. 2020). Finally, we included a control variable representing the length between survey years to account for the shorter temporal distance between earlier survey waves and the longer distance between later survey waves.

\footnotetext{
2 This dichotomous measure indicates whether the household meets the poverty threshold defined by the US Census Bureau based on the number of children in the household, number of adults, and the year of observation.
}

\section{Statistical Analyses}

To examine the relationship between exposure to gun violence and mothers' depression outcomes, we first used linear and logistic regression models and included our lagged outcome variable as a covariate. Our depression outcome scale was continuous. We used linear regression models for this outcome and included the dichotomous variable representing whether mothers witnessed a shooting as our predictor variable. For the two dichotomous depression outcomes (whether respondents met liberal depression criteria or conservative depression criteria), logistic regression models were used. As with the linear regression model, the dichotomous indicator for whether mothers witnessed a shooting was included as a predictor. We performed bivariable analyses and multivariable analyses with the full suite of covariates. Robust standard errors were calculated at the individual level. We then examined whether our results were robust when we used withinperson fixed-effects (FE) models. By examining whether witnessing gun violence was associated with a change in depression within individuals, these models parceled out unobserved, time-invariant heterogeneity and were thus less susceptible to omitted variable bias. Only time-varying covariates were included in these models (gender, race, and education were excluded), and the lagged outcome variable was excluded because the FE models measured change in the outcome. The disadvantage of these models is that they remove all observations for which there is no variation in the outcome, leading to a loss of power and an inability to examine those who had never experienced depression (Hill et al. 2019). As such, it is valuable to examine the lagged outcome and FE models in tandem to provide a comprehensive insight into the relationship between exposure to gun violence and mothers' depression and to guard against the limitations of each model. All analyses were conducted in STATA 16.

\section{Supplementary Analyses}

As noted above, maternal depression is likely to have spillover effects for family members' wellbeing. To more directly examine this possibility, we conducted a supplementary analysis using parental aggravation as an outcome. Parental aggravation was measured by the FFCWS with the following questions, "Being a parent is harder than I thought it would be," "I feel trapped by my responsibilities as a parent," "I find that taking care of my child(ren) is much more work than pleasure," and "I often feel tired, worn out, or exhausted from raising a family." We dichotomized the responses to these questions ( 1 = agree or strongly agree, $0=$ disagree or strongly disagree) and summed and averaged them to create a scale measure of parental aggravation. This scale is wellsupported and has been validated in the literature on family 
functioning (Bendheim-Thoman Center for Research on Child Wellbeing 2020).

For this analysis, we used structural equation models (SEM) which allowed us to examine whether witnessing a shooting had a direct relationship with parental aggravation, as well as an indirect relationship through maternal depression. We expected to observe both direct and indirect relationships given that maternal depression is associated with harsher parenting practices (Wolford et al. 2019; Yeh et al. 2016). Solely examining the direct relationship between witnessing a shooting and parental aggravation could therefore underestimate gun violence exposure's impact on parenting. We included the full suite of covariates that had been used for our depression outcomes, as well as a measure for child gender, the continuous measure for maternal depression, ${ }^{3}$ and a scale measure for child behavior problems, as all may be associated with parenting aggravation. The behavior problem measure was constructed from the Child Behavior Checklist, a list of 34 survey questions on children's behavior problems that parents were asked in each survey wave of the FFCWS (Bendheim-Thoman Center for Research on Child Wellbeing 2020). We summed the 34 questions into a standardized scale with a mean of 0 and standard deviation of 1 . Because multiple imputation does not support SEM in Stata, we used the original, non-imputed dataset.

\section{Results}

\section{Descriptive Statistics}

For the lagged outcomes models, we observe about 12,846 mother interviews in our analytic sample (observations varied modestly depending on the outcome in question), of which 744 $(5.8 \%)$ reported witnessing a shooting in any survey year (Table 1). Because the FE models relied on within-person change, they dropped observations for which we did not observe changes in the depression outcomes. As such, fewer mothers are observed in our FE analytic samples, particularly for our conservative depression criteria outcome. Nevertheless, we observed 3547 mother interviews in our FE samples for the conservative depression criteria, our most restrictive criteria. Of those mothers, $259(7.3 \%)$ had witnessed a shooting in the past year (Table 1).

We first examined the descriptive characteristics for our lagged outcome and FE analytic samples. On average, those who witnessed shootings were more likely to be persons of color and socioeconomically disadvantaged. Specifically, the descriptive statistics for our lagged outcome sample indicated that mothers who witnessed shootings were more likely to be

\footnotetext{
${ }^{3}$ The results did not vary if we used the dichotomous measures for whether mothers met depression criteria. For brevity, we therefore present the results using a single depression measure.
}

Black $(74.7 \%$ vs. $48.6 \%)$, in poverty $(61.8 \%$ vs. $36.6 \%)$, and have less than a high school degree (34.01 vs. 22.2). Mothers who witnessed shootings were also less likely to have a college degree (4\% vs. $15.6 \%$ ) and be married or cohabiting (38.6\% vs. $51.8 \%$ ). Further, those who witnessed a shooting had lower household incomes and lived in more disadvantaged neighborhoods and counties, on average. Mothers in the FE analytic sample displayed similar aggregate patterns (Table 1).

Indicatively, our descriptive statistics indicated that mothers who witnessed shootings were more likely to meet conservative and liberal criteria for depression $(21.1 \%$ vs. $11.2 \% ; 27.8 \%$ vs. $16.3 \%$ ) and have higher depression scores ( 0.44 vs. 0.08 ) than mothers who did not witness shootings. Mothers are also about 3-4 percentage points more likely to meet liberal or conservative depression criteria in prior waves than mothers who did not witness shootings, though mothers who witnessed shootings also exhibited greater changes in their depression scores and meeting criteria across waves than mothers who did not witness shootings (Table 1).

Similar disparities were observed in the descriptive statistics for our FE samples, though we also observed that mothers in our FE samples were more likely than mothers in our lagged outcome samples to meet criteria for depression regardless of whether they had witnessed a shooting. This is unsurprising given that the FE models relied on mothers who exhibited changes in depression criteria. Nevertheless, mothers who witnessed shootings in our FE sample underwent larger increases in depression scores and the proportion meeting depression criteria across waves than mothers who did not witness shootings (Table 1). As such, our descriptive statistics provide suggestive evidence that witnessing a shooting is associated with higher probabilities of meeting depression criteria.

\section{Regression Models}

In both our bivariable and multivariable lagged outcome models, witnessing a shooting was associated with significantly greater symptoms of depression and a significantly higher likelihood of meeting criteria for depression based on the conservative and liberal CIDI-SF definitions. These results held in both the bivariable and multivariable models, though prior diagnoses of depression and individuals' socioeconomic and marital statuses explained modest portions of those relationships. In the fully specified multivariable models, witnessing a shooting is associated with an increase in depression scores of $21.4 \%$ of a standard deviation and is associated with a $58.3 \%$ and $57.8 \%$ increase in the odds of meeting the liberal and conservative criteria for depression, respectively (Table 2).

The FE models largely confirmed the conclusions from the lagged outcome models. Specifically, those who witnessed a shooting experienced a significant increase in their depression scores and exhibited an approximately $32.5-39.2 \%$ increase 
Table 1 Characteristics of the mother-interview lagged outcome and fixed effect analytic samples ${ }^{\mathrm{a}}$

\begin{tabular}{|c|c|c|c|c|}
\hline \multirow[b]{2}{*}{ Characteristics } & \multicolumn{2}{|c|}{ Lagged outcome analytic sample } & \multicolumn{2}{|c|}{ Fixed effects analytic sample } \\
\hline & $\begin{array}{l}\text { Did not report } \\
\text { witnessing a shooting } \\
(N=12,102)\end{array}$ & $\begin{array}{l}\text { Reported witnessing } \\
\text { a shooting }(N=744)\end{array}$ & $\begin{array}{l}\text { Did not report } \\
\text { witnessing a } \\
\text { shooting }(N=3288)\end{array}$ & $\begin{array}{l}\text { Reported witnessing } \\
\text { a shooting }(N=259)\end{array}$ \\
\hline & $\mathrm{N}(\%)$ & $\mathrm{N}(\%)$ & $\mathrm{N}(\%)$ & $\mathrm{N}(\%)$ \\
\hline \multicolumn{5}{|l|}{$\mathrm{PCG}^{\mathrm{b}}$ race/ethnicity } \\
\hline White & 2767 (22.9) & $39(5)$ & $802(24.4)$ & $15(5.8)$ \\
\hline Black & $5877(48.6)$ & $556(74.7)$ & $1684(51.2)$ & $201(77.6)$ \\
\hline Latinx & $3058(25.3)$ & $134(18.0)$ & $720(21.9)$ & $36(13.9)$ \\
\hline Other & $400(3.3)$ & $15(2)$ & $82(2.5)$ & $7(2.7)$ \\
\hline \multicolumn{5}{|l|}{ PCG educational level } \\
\hline Less than HS degree & $2682(22.2)$ & $253(34.01)$ & $768(23.4)$ & $89(34.4)$ \\
\hline HS degree & $2851(23.6)$ & $192(25.8)$ & $783(23.8)$ & $63(24.3)$ \\
\hline Some college & $4680(38.7)$ & $269(36.2)$ & $1359(41.3)$ & $100(38.6)$ \\
\hline College+ & $1889(15.6)$ & $30(4)$ & $378(11.5)$ & $7(2.7)$ \\
\hline \multicolumn{5}{|l|}{$\mathrm{HH}^{\mathrm{c}}$ characteristics } \\
\hline PCG employed & $7648(63.2)$ & $364(48.9)$ & $1868(56.8)$ & $110(42.5)$ \\
\hline Logged HH income, mean (SE) & $10.16(0.013)$ & $9.47(0.058)$ & $10.01(0.026)$ & $9.52(0.081)$ \\
\hline $\mathrm{HH}$ in poverty & $4428(36.6)$ & $460(61.8)$ & $1355(41.2)$ & $161(62.2)$ \\
\hline PCG married/cohabit & $6274(51.8)$ & $287(38.6)$ & $1542(46.9)$ & $99(38.1)$ \\
\hline Biological parents married & $4095(33.8)$ & $127(17.0)$ & $878(26.7)$ & $39(14.9)$ \\
\hline Number of children in $\mathrm{HH}$, mean (SE) & $2.21(0.012)$ & $2.66(0.059)$ & $2.26(0.025)$ & $2.64(0.103)$ \\
\hline \multicolumn{5}{|l|}{ Contextual characteristics } \\
\hline County log violent crime rate, mean (SE) & $6.34(0.007)$ & $6.711(0.018)$ & $6.36(0.013)$ & $6.725(0.031)$ \\
\hline Tract $\%$ below poverty level, mean (SE) & $0.211(0.001)$ & $0.332(0.006)$ & $0.221(0.026)$ & $0.344(0.010)$ \\
\hline Parent aggravation score, mean (SE) & $0.01(0.006)$ & $0.19(0.028)$ & $0.15(0.013)$ & $0.29(0.048)$ \\
\hline \multicolumn{5}{|l|}{ Lagged depression } \\
\hline Depression score, mean (SE) & $0.11(0.008)$ & $0.24(0.039)$ & $0.608(0.021)$ & $0.612(0.073)$ \\
\hline Liberal depression criteria & $2123(17.5)$ & $158(21.2)$ & $1276(38.8)$ & $94(36.4)$ \\
\hline Conservative depression criteria & $1487(12.3)$ & $116(15.6)$ & $1023(31.1)$ & $75(28.8)$ \\
\hline \multicolumn{5}{|l|}{ Depression outcomes } \\
\hline Depression score, mean (SE) & $0.08(0.009)$ & $0.44(0.040)$ & $0.781(0.020)$ & $1.040(0.071)$ \\
\hline Liberal depression criteria & $1967(16.3)$ & $207(27.8)$ & $1516(46.1)$ & $138(53.3)$ \\
\hline Conservative depression criteria & $1361(11.2)$ & $157(21.1)$ & $1259(38.3)$ & $114(44.0)$ \\
\hline
\end{tabular}

${ }^{a}$ Sample characteristics are for the samples utilized in the lagged outcome and fixed effects models for conservative depression criteria. Sample characteristics are substantively very similar for the other outcomes utilized for the lagged outcome models

${ }^{\mathrm{b}} P C G$ primary caregiver

${ }^{\mathrm{c}} H H$ household

in the odds of meeting both the conservative and liberal criteria for depression (Table 2). We did not observe any subgroup differences in these relationships by race, ethnicity, or socioeconomic status.

\section{Supplementary Analyses}

In supplementary analyses, we examined the direct and indirect relationships between witnessing a shooting, maternal depression, and parental aggravation, using SEM. We found that witnessing a shooting had a direct and significant association with parental aggravation as well as an indirect relationship through maternal depression (Fig. 1). Cumulatively, witnessing a shooting was associated with a $15 \%$ standard deviation increase in parental aggravation scores. Approximately $90 \%$ of that association was the result of the direct relationship between witnessing a shooting and parental aggravation, and an additional $10 \%$ resulted from the indirect relationship between witnessing a shooting, maternal depression, and parental aggravation. Thus, witnessing a shooting may impact parenting 
Table 2 The relationship between exposure to a shooting and mothers' symptoms of and diagnoses of depression using multiple imputation

\begin{tabular}{|c|c|c|c|c|c|c|}
\hline & \multicolumn{2}{|c|}{ Depression index ${ }^{\mathrm{a}}$} & \multicolumn{2}{|l|}{ Liberal DC ${ }^{\mathrm{c}}$} & \multicolumn{2}{|c|}{ Conservative DC } \\
\hline & $\begin{array}{l}\text { Bivariate } \\
\beta[95 \% \mathrm{CI}]\end{array}$ & $\begin{array}{l}\text { Multivariable } \\
\beta[95 \% \mathrm{CI}]\end{array}$ & Bivariate OR $[95 \% \mathrm{CI}]$ & $\begin{array}{l}\text { Multivariable } \\
\text { OR [95\% CI] }\end{array}$ & $\begin{array}{l}\text { Bivariate } \\
\text { OR [95\% CI] }\end{array}$ & $\begin{array}{l}\text { Multivariable } \\
\text { OR [95\% CI] }\end{array}$ \\
\hline \multicolumn{7}{|l|}{ Lagged outcome models ${ }^{\mathrm{a}}$} \\
\hline Witnessed Shooting $=1$ & $\begin{array}{l}0.334^{* * * *} \\
{[0.245-0.422]}\end{array}$ & $\begin{array}{l}0.214^{* * * *} \\
{[0.133-0.294]}\end{array}$ & $\begin{array}{l}1.816^{\text {**** }} \\
{[1.518-2.173]}\end{array}$ & $\begin{array}{l}1.583^{\text {**** }} \\
{[1.309-1.913]}\end{array}$ & $\begin{array}{l}1.901^{* * * *} \\
{[1.558-2.319]}\end{array}$ & $\begin{array}{l}1.578^{\text {**** }} \\
{[1.281-1.943]}\end{array}$ \\
\hline$N$ & 12,883 & 12,883 & 12,871 & 12,871 & 12,846 & 12,846 \\
\hline \multicolumn{7}{|l|}{ Fixed effects models ${ }^{\mathrm{b}}$} \\
\hline Witnessed Shooting=1 & $\begin{array}{l}0.095^{*} \\
{[0.02-0.17]}\end{array}$ & $\begin{array}{l}0.091^{*} \\
{[0.02-0.17]}\end{array}$ & $\begin{array}{l}1.365^{*} \\
{[1.05-1.78]}\end{array}$ & $\begin{array}{l}1.392^{*} \\
{[1.06-1.82]}\end{array}$ & $\begin{array}{l}1.312^{\wedge} \\
{[0.98-1.76]}\end{array}$ & $\begin{array}{l}1.325^{\wedge} \\
{[0.98-1.79]}\end{array}$ \\
\hline$N$ & 12,954 & 12,954 & 4566 & 4566 & 3563 & 3563 \\
\hline Unique IDs & 4122 & 4122 & 1304 & 1304 & 1020 & 1020 \\
\hline
\end{tabular}

$\hat{p} p<0.1,{ }^{*} p<0.05,{ }^{* *} p<0.01,{ }^{* * *} p<0.001$

a All lagged outcome multivariable models are adjusted for: the outcome lagged one wave, race/ethnicity (White-ref., Black, Latinx, Other), mothers' highest level of education (less than high school-ref., high school degree, some college, college+), whether the mother is employed, logged total household income, whether the family is in poverty, whether the mother is married or cohabiting, whether the mother is married or cohabiting with the father of her child, the number of children in the household, state fixed effects, the logged violent crime rate in the county, the poverty rate of the Census tract, and the length (in years) between survey waves

${ }^{\mathrm{b}}$ All fixed effects multivariable models are adjusted for time-varying covariates including: whether the mother is employed, logged total household income, whether the family is in poverty, whether the mother is married or cohabiting, whether the mother is married or cohabiting with the father of her child, the number of children in the household, the logged violent crime rate in the county, the poverty rate of the Census tract, and the length (in years) between survey waves

${ }^{\mathrm{c}} D C$ depression criteria

Source: Fragile Families and Child Wellbeing Study (FFCWS)

outcomes directly and indirectly by increasing mothers' risk of depression. We found substantively the same relationships using lagged outcome and FE models with our multiple imputation samples, though neither model clearly highlights the direct and indirect relationships between these measures. We therefore focused on the SEM models here.

\section{Discussion}

In this study, we found that $5.8-7.3 \%$ of low-income mothers in urban areas witnessed shootings in their local communities, a meaningful proportion. For these mothers, witnessing gun violence in their community was associated with significantly

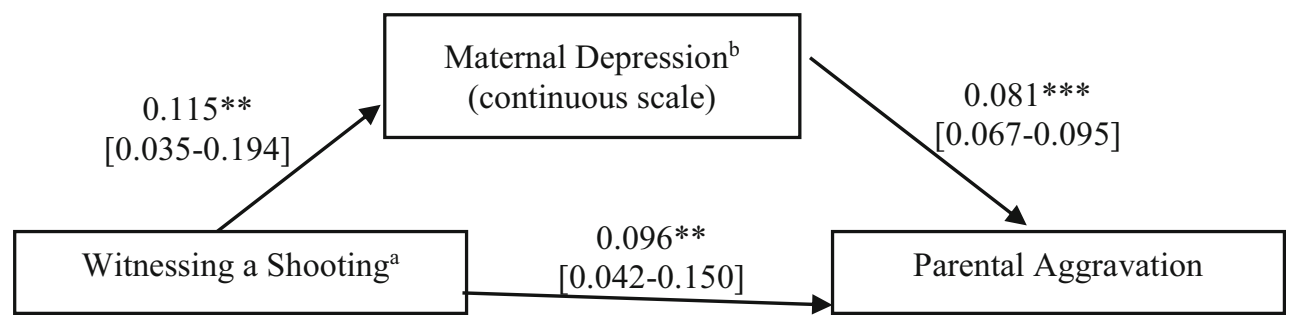

Fig. 1 The path diagram showing the modeled relationships between exposure to a shooting, maternal depression, and parental aggravation using structural equation models (coefficients and confidence intervals are reported for each pathway); Source: Fragile Families and Child Wellbeing Study (FFCWS); $n=8616$. a The model of the direct pathway between witnessing a shooting and parental aggravation adjusted for the outcome lagged one wave, race/ethnicity (White-ref., Black, Latinx, Other), mothers' highest level of education (less than high school-ref., high school degree, some college, college+), whether the mother is employed, logged total household income, whether the family is in poverty, whether the mother is married or cohabiting, whether the mother is married or cohabiting with the father of her child, the number of children in the household, state fixed effects, the logged violent crime rate in the county, the poverty rate of the Census tract, and the length (in years) between survey waves, child behavior problems, child gender, and the continuous maternal depression scale. $b$ The indirect pathway modeled between witnessing a shooting and maternal depression included race/ethnicity (White-ref., Black, Latinx, Other), mothers' highest level of education (less than high school-ref., high school degree, some college, college+), whether the mother is employed, logged total household income, whether the family is in poverty, whether the mother is married or cohabiting, whether the mother is married or cohabiting with the father of her child, the number of children in the household, state fixed effects, the logged violent crime rate in the county, the poverty rate of the Census tract, and the length (in years) between survey waves 
more symptoms of depression and with meeting conservative and liberal criteria for depression. In fact, witnessing a shooting was associated with a roughly $32-58 \%$ increase in the odds of having depression depending on the model and depression criteria used. These are highly meaningful increases, and these relationships held after accounting for numerous characteristics of the mother, her household, and residential context that might shape the relationship between witnessing a shooting and depression. We also find that witnessing a shooting has a direct association with parenting aggravation, as well as an indirect association through maternal depression, reinforcing that these relationships are likely to have spillover consequences for family members' wellbeing.

These findings are important for scholars and policymakers. Our focus on community gun violence is a contribution to the literature on violence and mental health, which has largely focused on victimization and/or broader measures of community violence and has not specifically focused on gun violence. Ours is among the few studies to observe these associations for mothers, rather than children, adolescents, victims, or perpetrators. The findings observed in this study therefore contribute to the literatures on mental health, gun violence, and parent outcomes.

Moreover, while resources are frequently directed toward the victims of gun violence, our findings demonstrate the importance of providing resources for coping with trauma on a wider, community-level basis. This is especially important because women exposed to local violence are more likely than unexposed women to experience other forms of violent victimization (i.e., polyvictimization) (Willie et al. 2017) and less likely to have access to healthcare resources (King and Khanijahani 2020). Similarly, Black, Latinx, and lowincome mothers are disproportionately exposed to gun violence and less likely to have access to healthcare resources and mental health facilities (Bridges 2011; Dimick et al. 2013; White et al. 2012). Latinx and, especially, Black mothers are also more likely to experience additional stressors such as incarceration or the incarceration of a loved one (Wildeman 2009), poverty, and discrimination (Oh et al. 2020). While Black and Latinx women are less likely than White women to report depression (Oh et al. 2020), our findings suggest that gun violence occurs in tandem with numerous stressors that are likely to take a toll on mothers' mental health. These relationships could, in turn, exacerbate racial and socioeconomic disparities in wellbeing. Our findings therefore indicate that mothers exposed to gun violence are likely to be an important, underserved group of individuals who are vulnerable to depression.

Further, we demonstrate that the costs of gun violence are underestimated unless the effect of gun violence on community members is accounted for. These effects include the direct effects of gun violence on witnesses and its indirect effects on the loved ones of witnesses who may be impacted if their kith or kin experience depression as a result of their exposure. We document that one spillover effect may be an increase in parental aggravation, which is associated with lower quality parent-child relationships and child behavior problems (Ward and Lee 2020). Because low-income children are more likely to be exposed to violence and live in single-parent families and families with greater parenting stress (Cooper et al. 2009), exposure to gun violence may exacerbate disparities in child wellbeing. As noted above, maternal depression is also associated with family functioning across a wide number of dimensions not explored here. Our findings are therefore important for illustrating that an important feature of residential contexts, local occurrences of gun violence, shapes the outcomes of mothers and their families.

Additionally, our findings demonstrate the importance of improving individuals' access to healthcare resources and mental health facilities in areas that are exposed to gun violence. Developing support groups that are targeted to community members who live in areas affected by gun violence may be especially useful. Providing targeted supports to parents to help manage the stresses of parenting may also help ameliorate the association between local violence, mental health, and parenting outcomes. These supports could include mental health counseling, as well as access to low-cost, high-quality childcare and after-school resources that help ease the stress of parenting in a neighborhood that may be higher risk for children and family members (Craig and Churchill 2018). Finally, the presence of local community groups devoted to reducing violence is associated with decreases in local crime rates (Sharkey et al. 2017). Empowering communities through such local groups may not only help alleviate gun violence but could be beneficial for mental health as well.

\section{Limitations}

These findings are subject to limitations. First, we were only able to observe mothers across 4 waves of the FFCWS. During this time period, mothers were surveyed when their children were $3,5,9$, and 15 . As such, it would be valuable to have more waves of data at smaller, more regular intervals in order to better isolate the relationship between witnessing a shooting and mothers' symptoms of depression and to ensure that we capture the correct time ordering of witnessing gun violence and experiencing depression. Moreover, having fewer survey waves tends to lead to conservative estimates using FE models (Hill et al. 2019). Our ability to perform both lagged outcome and FE models helped account for the limitations of each method and the survey design. Nevertheless, these limitations are important to consider when interpreting the results, especially regarding potential omitted timevarying characteristics and experiences that occurred between survey waves. Indeed, it is possible that some of our respondents witnessed gun violence between survey waves. As a 
result, our comparison sample may include individuals who witnessed gun violence and who are suffering negative mental health outcomes as a result. If this is the case, our estimates may be conservative. This possibility is reinforced by prior research showing that children exposed to violence tend to be exposed multiple times, with these multiple exposures corresponding to progressively worse mental health outcomes (Copeland et al. 2007, 2010). As such, results of this observational study should be interpreted as associational rather than causal.

Additionally, in our lagged outcome models, we would ideally include fixed effects at a finer geographic level of aggregation than states to better account for neighborhoodand city-level variation. However, too few individuals in the FFCWS shared Census tracts to use fixed effects at this level, and city identifiers were not available in every year. Our ability to include measures of county and neighborhood characteristics helps ameliorate some of this concern. Finally, the FFCWS focuses on larger urban areas and low-income families. Our results cannot therefore be generalized to the broader population.

\section{Conclusion}

This study provides important insights into the relationship between community gun violence and mothers' risk of depression, demonstrating that witnessing gun violence in one's community is associated with significant and meaningful increases in mothers' symptoms of depression, the probability that they meet the criteria for diagnosable depression, and their reports of parenting aggravation. These associations demonstrate the importance of providing local mental health and community resources for those who are exposed to violence and who may experience long-lasting trauma as a result (Rowhani-Rahbar et al. 2019).

Funding Partial support for this research came from a Eunice Kennedy Shriver National Institute of Child Health and Human Development research infrastructure grant, P2C HD042828, to the Center for Studies in Demography \& Ecology at the University of Washington. This research was also supported by a grant from the Washington State legislature to support the Firearm Injury \& Policy Research Program at the Harborview Injury Prevention and Research Center.

\section{Compliance with Ethical Standards}

Conflict of Interest The authors declare that they have no conflict of interest.

Ethics Approval This study was deemed minimal risk and was approved by the University of Washington Institutional Review Board (IRB).

Consent to Participate The study relied on precollected data and involved no contact with participants on the part of the research team. Informed consent was obtained from all individuals who participated in the study by the Fragile Families and Child Wellbeing Study at baseline and at all subsequent waves.

\section{References}

Bagner, D., Pettit, J., Lewinsohn, P., \& Seeley, J. (2010). Effect of maternal depression on child behavior: A sensitive period? Journal of the American Academy of Child \& Adolescent Psychiatry, 29(7), 699-707.

Barnes, M., Bloom, A., Cox, K., Lessof, C., \& Walker, A. (2006). The social exclusion of older people: Evidence from the first wave of the English longitudinal study of ageing (ELSA), Final Report. Office of the Deputy Prime Minister.

Beardslee, J., Mulvey, E., Schubert, C., Allison, P., Infante, A., \& Pardini, D. (2018). Gun and non-gun related violence exposure and risk of subsequent gun carrying among male juvenile offenders. Journal of the American Academy of Child \& Adolescent Psychiatry, 57(4), 274-279.

Bendheim-Thoman Center for Research on Child Wellbeing. (2020). User's guide for the fragile families and child wellbeing study public data, Year 15. https://fragilefamilies.princeton.edu/sites/ fragilefamilies/files/year_15_guide.pdf\#page $=38$. Accessed 20 May, 2020.

Bridges, K.M. (2011). Reproducing race: An ethnography of pregnancy as a site of racialization. Berkeley, CA: University of California Press.

Clark, C., Ryan, L., Kawachi, I., Canner, M., Berkman, L., \& Wright, R. (2008). Witnessing community violence in residential neighborhoods: A mental health hazard for urban women. Journal of Urban Health, 85, 22-38.

Cohen-Mansfield, J., Hazan, H., Lerman, Y., \& Shalom, V. (2016). Correlates and predictors of loneliness in older adults: A review of quantitative results informed by qualitative insights. International Psychogeriatrics, 28(4), 557-576.

Cooper, C., McLanahan, S., Meadows, S., \& Brooks-Gunn, J. (2009). Family structure transitions and maternal parenting stress. Journal of Marriage and Family, 71, 558-574.

Copeland, W., Keeler, G., Angold, A., \& Costello, E. J. (2007). Traumatic events and posttraumatic stress in childhood. Archives of General Psychiatry, 64, 577-584.

Copeland, W., Keeler, G., Angold, A., \& Costello, E. J. (2010). Posttraumatic stress without trauma in children. American Journal of Psychiatry, 167, 1059-1065.

Craig, L., \& Churchill, B. (2018). Parenting stress and the use of formal and informal child care: Associations for fathers and mothers. Journal of Family Issues, 39(12), 3203-3224.

Cummings, E. M., \& Davies, P. (1994). Maternal depression and child development. Journal of Child Psychol and Psychiatry, 35(1), 73112.

Dawson, C., Wu, W., Fennie, K., Ibanez, G., Cano, M., Pettit, J., \& Trepka, M. J. (2019). Perceived neighborhood social cohesion moderates the relationship between neighborhood structural disadvantage and adolescent depressive symptoms. Health \& Place, 56, 88-98.

DeSantis, A., Troxel, W., Beckman, R., Ghosh-Dastidar, B., Hunter, G., Hale, L., et al. (2016). Is the association between neighborhood characteristics and sleep quality mediated by psychological distress? An analysis of perceived and objective measures of 2 Pittsburgh neighborhoods. Sleep Health, 2(4), 277-282.

Dimick, J., Ruhter, J., Sarrazin, M. V., \& Birkmeyer, J. (2013). Black patients more likely than whites to undergo surgery at low-quality hospitals in segregated regions. Health Affairs, 32(6), 1046-1053. 
Elgar, F., McGrath, P., Waschbusch, D., Stewart, S., \& Curtis, L. (2004). Mutual influences on maternal depression and child adjustment problems. Clinical Psychology Review, 24(4), 441-459.

Erickson, N., Julian, M., \& Muzik, M. (2019). Perinatal depression, PTSD, and trauma: Impact on mother-infant attachment and interventions to mitigate the transmission of risk. International Review of Psychiatry, 31(3), 245-263.

Evans, E., Li, L., Buoncristiani, S., \& Hser, Y.-I. (2011). Perceived neighborhood safety, recovery capital, and successful outcomes among mothers 10 years after substance abuse treatment. Substance Use \& Misuse, 49(11), 1491-1503.

Fahimi, J., Larimer, E., Hamid, W., Anderson, E., Schnorr, C., Yen, I., et al. (2016). Long-term mortality of patients surviving firearm violence. Injury Prevention, 22(2), 129-134.

Fowler, P., Tompsett, C., Braciszewski, J., Jacques-Tiura, A., \& Baltes, B. (2009). Community violence: A meta-analysis on the effect of exposure and mental health outcomes of children and adolescents. Development and Psychopathology, 21(1), 227-259.

Gergo, B., Cherrie, M., Curtis, S., Dibben, C., \& Pearce, J. (2020). Changing levels of local crime and mental health: A natural experiment using self-reported and service use data in Scotland. Journal of Epidemiology \& Community Health.

Goodman, S., Rouse, M., Connell, A., Broth, M. R., Hall, C., \& Heyward, D. (2011). Maternal depression and child psychopathology: A meta-analytic review. Clinical Child and Family Psychology Review, 14, 1-27.

Hill, T., Davis, A., Roos, J. M., \& French, M. (2019). Limitations of fixed-effects models for panel data. Sociological Perspectives, 63(3), 356-369.

Huang, X., King, C., \& McAtee, J. (2018). Exposure to violence, neighborhood context, and health-related outcomes in low-income urban mothers. Health \& Place, 54, 138-148.

Kagawa, R., Cerda, M., Rudolph, K., Pear, V., Keyes, K., \& Wintemute, G. (2018). Firearm involvement in violent victimization and mental health: An observational study. Annals of Internal Medicine, 169(8), 584-585.

Kagawa, R., Pear, V., Rudolph, K., Keyes, K., Cerda, M., \& Wintemute, G. (2020). Distress level and daily functioning problems attributed to firearm victimization: Sociodemographic-specific responses. Annals of Epidemiology, 41, 35-42.

Kane, R. (2011). The ecology of unhealthy places: Violence, birthweight, and the importance of territoriality in structurally disadvantaged communities. Social Science \& Medicine, 73(11), 1585-1592.

Kessler, R. C., Andrews, G., Mroczek, D., Ustun, T. B., \& Wittchen, H. U. (1998). The World Health Organization composite international diagnostic interview short-form (CIDI-SF). International Journal of Methods in Psychiatric Research, 7(4), 171-185.

King, C., \& Khanijahani, A. (2020). Unmet health care needs among children of mothers exposed to violence. Child Abuse \& Neglect, $101,1-8$.

Kingsbury, M., Clayborne, Z., Colman, I., \& Kirkbride, J. (2020). The protective effect of neighborhood social cohesion on adolescent mental health following stressful life events. Psychological Medicine, 50(8), 1292-1299.

Kneeshaw-Price, S., Saelens, B., Sallis, J., Frank, L., Grembowski, D., Hannon, P., Smith, N., \& Chan, K. C. G. (2015). Neighborhood crime-related safety and its relation to children's physical activity. Journal of Urban Health, 92, 472-489.

Knopov, A., Rothman, E., Cronin, S., Franklin, L., Cansever, A., Potter, F., et al. (2019). The role of racial residential segregation in BlackWhite disparities in firearm homicide at the state level in the U.S. Journal of the National Medical Association, 111(1), 62-75.

Montgomerie, J., Lawrence, A., LaMotte, A., \& Taft, C. (2015). The link between posttraumatic stress disorder and firearm violence. Aggression and Violent Behavior, 21, 39-44.
Newbury, J., Arseneault, L., Caspi, A., Moffitt, T., Odgers, C., \& Fischer, H. (2018). Cumulative effects of neighborhood social adversity and personal crime victimization on adolescent psychotic experiences. Schizophrenia Bulletin, 44(2), 348-358.

Oh, H., Stickley, A., Koyanagi, A., Yau, R., \& DeVylder, J. (2020). Discrimination and suicidality amongst racial and ethnic minorities in the U.S. Journal of Affective Disorders, 245, 517-523.

Overstreet, S. (2000). Exposure to community violence: Defining the problem and understanding the consequences. Journal of Child and Family Studies, 9, 7-25.

Pratt, M., Zeev-Wolf, M., Goldstein, A., \& Feldman, R. (2019). Exposure to early and persistent maternal depression impairs the neural basis of attachment in preadolescence. Progress in NeuroPsychopharmacology and Biological Psychiatry, 93(13), 21-30.

Ranney, M., Karb, R., Ehrlich, P., Bromwich, K., Cunningham, R., Beidas, R., \& For the FACTS Consortium. (2019). What are the long-term consequences of youth exposure to firearm injury, and how do we prevent them? A scoping review. Journal of Behavioral Medicine, 42(4), 724-740.

Rossin-Slater, M., Schnell, M., Schwandt, H., Trejo, S., \& Uniat, L. (2019). Local exposure to school shootings and youth antidepressant use. NBER Working Paper No. 26563.

Rowhani-Rahbar, A., Zatzick, D., Wang, J., Mills, B., Simonetti, J., Fan, M., et al. (2015). Firearm-related hospitalization and risk for subsequent violent injury, death, or crime perpetration. Annals of Internal Medicine, 162(7), 492-500.

Rowhani-Rahbar, A., Fan, M., Simonetti, J., Lyons, V., Wang, J., Zatzick, D., \& Rivara, F. (2016). Violence perpetration among patients hospitalized for unintentional and assault-related firearm injury. Annals of Internal Medicine, 165(12), 841-847.

Rowhani-Rahbar, A., Zatzick, D., \& Rivara, F. (2019). Long-lasting consequences of gun violence and mass shootings. JAMA, 321(18), $1765-1766$.

Sharkey, P., Torrats-Espinosa, G., \& Takyar, D. (2017). Community and the crime decline: The causal effect of local nonprofits on violent crime. American Sociological Review, 82(6), 1214-1240.

Shenassa, E.D, Catlin, S.N., \& Buka, S.L. (2003). Lethality of firearms relative to other suicide methods: . Journal of Epidemiology \& Community Health, 57(2),120-124.

Stretesky, P., \& Pogrebin, M. (2007). Gang-related gun violence: Socialization, identity, and self. Journal of Contemporary Ethnography, 36(1), 85-114.

Theall, K., Shirtcliff, E., Dismukes, A., Wallace, M., \& Drury, S. (2017). Association between neighborhood violence and biological stress in children. JAMA Pediatrics, 171(1), 53-60.

Tracy, B., Smith, R., Miller, K., Clayton, E., Bailey, K., Gerrin, C., et al (2019). Community distress predicts youth gun violence. Journal of Pediatric Surgery, 54(11), 2375-2381.

Ward, K., \& Lee, S. (2020). Mothers' and fathers' parenting stress, responsiveness, and child wellbeing among low-income families. Children and Youth Services Review, 116, 1-9.

Wells, W., \& Horney, J. (2002). Weapon effects and individual intent to do harm: Influences on the escalation of violence. Criminology, 40(2), 265-296.

White, K., Haas, J. S., \& Williams, D. R. (2012). Elucidating the role of place in health care disparities: The example of racial/ethnic residential segregation. Health Services Research, 47(3), 1278-1299.

Wildeman, C. (2009). Parental imprisonment, the prison boom, and the concentration of childhood disadvantage. Demography, 46(2), 265280.

Wilkinson, R., Kawachi, I., \& Kennedy, B. (2008). Mortality, the socia environment, crime and violence. Sociology of Health \& Illness, 20(5), 578-597.

Willie, T., Powell, A., Lewis, J., Callands, T., \& Kershaw, T. (2017). Who is at risk for intimiate partner violence victimization: Using latent class analysis to explore interpersonal polyvictimization and 
polyperpetration among pregnant young couples. Violence and Victims, 32(3), 545-564.

Wilson-Genderson, M., \& Pruchno, R. (2013). Effects of neighborhood violence and perceptions of neighborhood safety on depressive symptoms of older adults. Social Science \& Medicine, 85, 43-49.

Center for Disease Control \& Injury Prevention, Web-Based Injury Statistics Query and Reporting Systems (WISQARS) (2020) Fatal injury data. Center for Disease Control \& Injury Prevention. https:// www.cdc.gov/injury/wisqars/fatal.html. Accessed 8 June 2020.

Wolford, S., Cooper, A., \& McWey, L. (2019). Maternal depression, maltreatment history, and child outcomes. American Journal of Orthopsychiatry, 89(2), 181-191.

Wong, B., Bernstein, S., Jay, J., \& Siegel, M. (2020). Differences in racial disparities in firearm homicide across cities: The role of racial residential segregation and gaps in structural disadvantage. Journal of the National Medical Association in press.

Yeh, Z.-T., Huang, Y.-H., \& Liu, S.-I. (2016). Maternal depression and adolescent emotions: The role of family functioning. Journal of Child and Family Studies, 25, 2189-2200.

Yu, E., \& Lippert, A. (2016). Neighborhood crime rate, weight-related behaviors, and obesity: A systematic review of the literature. Sociology Compass, 10(3), 187-207.

Publisher's Note Springer Nature remains neutral with regard to jurisdictional claims in published maps and institutional affiliations. 